\title{
PENGARUH STRATEGI PELAKSANAAN KOMUNIKASI TERAPEUTIK TERHADAP RESIKO PERILAKU KEKERASAN PADA PASIEN GANGGUAN JIWA DI RUMAH SAKIT JIWA PROVINSI JAMBI
}

\author{
Vevi Suryenti Putri ${ }^{1)}$, Restia Mella $\mathrm{N}^{2)}$ dan Salvita Fitrianti ${ }^{3)}$ \\ Program Studi S1 Keperawatan STIKBA $1,2,3)$ \\ Email : vevisuryentiputri.2010@gmail.com
}

\begin{abstract}
Schizophrenic patients such as violent behavior violent behavior is a form of behavior that aims to injure a person physically and psychologically. To overcome violent behavior in schizophrenic patients it is necessary to take anticipatory strategies, in the form of therapeutic communication. The purpose of this study is to see whether there is an effect of therapeutic communication therapy on patients at risk of violent behavior in the Inpatient Room of Jambi Provincial Hospital. The study was conducted on 12-19 July 2018. The research design used was pre-experimental design with one group pre-test and post-test design. Respondents in this study were all schizophrenic patients with a risk of violent behavior in the inpatient ward of the Regional Psychiatric Hospital of Jambi Province as many as 98 people with a total sample of 20 respondents. Data collection was done by proportional random sampling technique. The results showed that before therapeutic communication therapy was known, most respondents had poor behavior (maladaptive) with a mean of 40.50, and therapeutic communication therapy was known to increase the score of behavior better (adaptive) with mean 43.90. The results showed that there was a significant effect of therapeutic communication therapy in addressing the problem of violent behavior in schizophrenic patients with a p-value of 0.013 ( $p$-value $<0.05$ ).
\end{abstract}

Key Words : Therapeutic Communication, Implementation Strategy, Violence Behavior

\begin{abstract}
ABSTRAK
Pasien skizofrenia seperti perilaku kekerasan perilaku kekerasan merupakan suatu bentuk perilaku yang bertujuan untuk melukai seseorang secara fisik maupun psikologis. Untuk mengatasi perilaku kekerasan pada pasien skizofrenia perlu dilakukan tindakan strategi antisipatif, berupa komunikasi terapeutik. Tujuan penelitian ini adalah untuk melihat apakah ada pengaruh terapi komunikasi terapeutik terhadap pasien resiko perilaku kekerasan di Ruang Rawat Inap RSJD Provinsi Jambi.Penelitian dilakukan pada tanggal 12 - 19 Juli 2018.Desain penelitian yang digunakan adalah pre-experimental design dengan one group pre-test and post-test design. Responden dalam penelitian ini adalah seluruh pasien skizofrenia dengan resiko perilaku kekerasan yang berada di ruang rawat inap RSJ Propinsi Jambi sebanyak 98 orang dengan jumlah sampel sebanyak 20 responden. Pengumpulan data dilakukan dengan teknik proporsional random sampling. Hasil penelitian menunjukkan sebelum dilakukan terapi komunikasi terapeutik diketahui sebagian besar responden mempunyai perilaku yang kurang baik (maladaptif) dengan mean 40.50, dan diberikan terapi komunikasi terapeutik diketahui terjadi peningkatan skor perilaku yang lebih baik (adaptif) dengan mean 43,90. Hasil penelitian menunjukkan bahwa ada pengaruh yang signifikan terapi komunikasi terapeutik dalam mengatasi masalah perilaku kekerasan pada pasien skizofrenia denganp-value 0,013 (p-value <0,05).
\end{abstract}

Kata kunci : :Komunikasi Terapeutik, Strategi Pelaksanaan, Perilaku Kekerasan 


\section{PENDAHULUAN}

Menurut WHO (World Health Organization) kesehatan jiwa bukan hanya tidak ada gangguan jiwa, melainkan mengandung berbagai karakteristik yang positif yang menggambarkan keselarasan dan keseimbangan kejiwaan yang mencerminkan kedewasaan pribadinya, kondisi yang memungkinkan perkembangan fisik, intelektual, emosional secara optimal dari seseorang dan perkembangan ini berjalan selaras dengan orang lain. ${ }^{1}$

Gangguan jiwa berat merupakan gangguan jiwa yang ditandai oleh terganggunya kemampuan menilai realitas atau tilikan (insight) yang buruk. Gejala yang menyertai gangguan ini antara lain berupa ilusi, waham, gangguan proses pikir, kemampuan berpikir, serta tingkah laku aneh, misalnya agresivitas atau katatonik. Gangguan jiwa berat dikenal dengan sebutan psikosis dan salah satu contoh psikosis adalah skizofrenia. Angka prevalensi seumur hidup skizofrenia di dunia bervariasi berkisar 4 permil sampai dengan 1,4 persen.$^{2}$ Menurut Ikatan Dokter Indonesia (2016), satu dari empat orang dewasa akan mengalami masalah kesehatan jiwa pada satu waktu dalam hidupnya. Data WHO (World Health Organization, 2016) menunjukkan, terdapat sekitar 35 juta orang terkena depresi, 60 juta orang terkena bipolar, 21 juta terkena skizofrenia. Berdasarkan data yang diperoleh dari Riset kesehatan dasar (2013) prevalensi gangguan jiwa berat pada penduduk Indonesia 1,7 per mil. Gangguan jiwa berat terbanyak di Aceh, DI Yogyakarta,
Sulawesi Selatan, Bali, dan Jawa Tengah.Prevalensi gangguan mental emosional pada penduduk Indonesia 6 persen. Provinsi dengan prevalensi ganguan mental emosional tertinggi adalah Sulawesi Tengah, Sulawesi Selatan, Jawa Barat, Yogyakarta, dan Nusa Tenggara Timur. Sedangkan prevalensi gangguan jiwa berat provinsi Jambi adalah $0,9 \%{ }^{2}$ Berdasarkan data yang di peroleh dari Rekam Medik Rumah Sakit Jiwa Daerah Jambi, diketahui jumlah pasien skizofrenia berdasarkan diagnosa medis pada bulan Januari s/d September tahun 2016 berjumlah 1.262 orang dengan persentase 45,5 $\%$ merupakan penyakit jiwa yang penderitanya lebih banyak diruang rawat inap.

Tabel 1.Jumlah Pasien Skizofrenia Berdasarkan Diagnosa Keperawatan di Ruang Rawat Inap Rumah Sakit Jiwa Daerah Jambi Pada Bulan Januari-Mei tahun 2018.

\begin{tabular}{llccc}
\hline No & Ruangan & Halusinasi & PK & DPD \\
\hline $\mathbf{1}$ & Epsilon & 143 & $\mathbf{3 6}$ & 0 \\
$\mathbf{2}$ & Srikandi & 65 & $\mathbf{7}$ & 0 \\
$\mathbf{3}$ & Arimbi & 224 & $\mathbf{6}$ & 0 \\
$\mathbf{4}$ & Beta & 169 & $\mathbf{0}$ & 0 \\
$\mathbf{5}$ & Arjuna & 192 & $\mathbf{0}$ & 0 \\
$\mathbf{6}$ & Yudistira & 209 & $\mathbf{0}$ & 0 \\
$\mathbf{7}$ & Gama & 125 & $\mathbf{0}$ & 79 \\
$\mathbf{8}$ & Alfha & 695 & $\mathbf{3 3}$ & 0 \\
$\mathbf{9}$ & Shinta & 133 & $\mathbf{5}$ & 0 \\
$\mathbf{1 0}$ & Delta & 165 & $\mathbf{3}$ & 22 \\
$\mathbf{1 1}$ & Pega & 72 & $\mathbf{1}$ & 12 \\
$\mathbf{1 2}$ & Teta & 337 & $\mathbf{6}$ & 2 \\
$\mathbf{1 3}$ & Sigma & 229 & $\mathbf{1}$ & 1 \\
$\mathbf{1 4}$ & Omega & 88 & $\mathbf{0}$ & 5 \\
& Jumlah & 3.375 & $\mathbf{9 8}$ & 121 \\
\hline
\end{tabular}

Sumber : Buku Mutasi Rawat Inap Rumah Sakit Jiwa Daerah Jambi Pada Bulan Januari-Mei Tahun 2018. 
Perilaku kekerasan merupakan suatu bentuk perilaku yang bertujuan untuk melukai seseorang secara fisik maupun psikologis. Berdasarkan definisi tersebut maka perilaku kekerasan dapat dilakukan secara verbal, diarahkan pada diri sendiri, orang lain, dan lingkungan . ${ }^{4}$ Perilaku kekerasan pada orang lain adalah tindakan agresif yang ditujukan untuk melukai atau membunuh orang lain. Perilaku kekerasan pada lingkungan dapat berupa perilaku merusak lingkungan, melempar kaca, genting dan semua yang ada di lingkungan..$^{5}$

$$
\text { Menurut Afnuhazi (2015), }
$$

faktor predisposisi yang
menyebabkan perilaku kekerasan antara lain, psikologis, perilaku, sosial budaya, dan bioneurologis. Sedangkan untuk faktor presipitasi itu sendiri dapat bersumber dari klien, lingkungan dan interaksi dengan orang lain. Penyebab dari perilaku kekerasan yaitu seperti kelemahan fisik (penyakit fisik), keputusasaan, ketidakberdayaan, dan kurang percaya diri. Untuk faktor penyebab dari perilaku kekerasan yang lain seperti situasi lingkungan yang terbiasa dengan kebisingan, padat, interaksi sosial yang proaktif, kritikan yang mengarah pada penghinaan, dan kehilangan orang yang di cintai (pekerjaan). Marah merupakan perasaan jengkel yang timbul sebagai respons terhadap kecemasan (kebutuhan yang tidak terpenuhi) yang dirasakan sebagai ancaman. Rentang respon kemarahan dari perilaku kekerasan dapat di gambarkan sebagai berikut, assertif, frustasi, pasif, agresif, dan mengamuk. ${ }^{5}$
Upaya yang digunakan untuk mengontrol perilaku kekerasan yaitu penatalaksanaan medis seperti: farmakologi, terapi modalitas, terapi keluarga, dan terapi kelompok (Afnuhazi,2015). Untuk penatalaksanaan keperawatan menurut Yosep (2016) bahwa perawat dapat mengimplementasikan berbagai cara untuk mencegah dan mengelola perilaku kekerasan melalui: strategi preventif (kesadaran diri, pendidikan klien, latihan asertif), strategi antisipatif (komunikasi, perubahan lingkungan, tindakan perilaku, psikofarmakologi), strategi pengurungan (managemen krisis, seclusion, restrains). ${ }^{1}$

Komunikasi terapeutik merupakan media utama yang digunakan untuk mengaplikasikan proses keperawatan dalam lingkungan kesehatan jiwa. Keterampilan perawat dalam komunikasi terapeutik mempengaruhi keefektifan banyak intervensi dalam keperawatan jiwa. Terapeutik merupakan segala sesuatu yang memfasilitasi proses penyembuhan. Komunikasi terapeutik itu sendiri merupakan komunikasi yang direncanakan dan dilakukan untuk membantu penyembuhan/pemulihan pasien .4 Komunikasi terapeutik ini dapat dilakukan untuk membantu proses penyembuhan pada pasien harga diri rendah, halusinasi, defisit perawatan diri dan perilaku kekerasan ${ }^{5}$ Perlu adanya hubungan saling percaya yang didasari oleh keterbukaan, memahami dan pengertian akan kebutuhan, harapan dan kepentingan masing-masing. Waktu yang paling efektif dalam melakukan komunikasi 
terapeutik adalah 3 kali dalam sehari yaitu pagi, siang dan malam hari (Simamora,2011).

Tujuan komunikasi terapeutik membantu klien untuk menjelaskan dan mengurangi beban perasaan dan pikiran serta dapat mengambil tindakan untuk mengubah situasi yang ada bila klien percaya pada hal yang diperlukan, mengurangi keraguan, membantu dalam hal mengambil tindakan yang efektif dan mempertahankan kekuatan egonya serta mempengaruhi orang lain, lingkungan fisik dan dirinya sendiri. ${ }^{5}$

Berdasarkan survey awal hasil wawancara yang dilakukan sebelum penelitian oleh peneliti terhadap 2 orang Kepala Ruangan, 4 orang perawat, dan 8 orang pasien di Rumah Sakit Jiwa Daerah Provinsi Jambi. Wawancara dan observasi dilakukan pada tanggal 23-25 April 2018, di Rumah Sakit Jiwa Daerah Provinsi Jambi terdapat 15 ruangan. Dari data yang didapat tahun 2018 terdapat jumlah pasien skizofrenia dengan perilaku kekerasan adalah 170 orang. Hasil wawancara diketahui kepala ruangan Pega mengatakan bahwa perawat di Rumah Sakit Jiwa Daerah Jambi sudah melakukan komunikasi terapeutik dengan menggunakan SP (Strategi Pelaksanaan) sesuai dengan masalah yang dialami pasien. Kepala ruangan Epsilon juga mengatakan bahwa perawat kerap sekali mengalami hambatan saat berinteraksi dengan pasien seperti pada saat menghadapi pasien yang kurang kooperatif untuk berkomunikasi/berinteraksi, saat pasien masih dominan dikuasai ketika pasien yang sering kali menunjukkan perilaku kekerasan.
Peneliti melakukan wawancara kepada 4 orang perawat yang bekerja di rumah sakit jiwa. Dua orang perawat di ruang Alfa mengatakan bahwa diruangan tersebut belum effektif apabila dilakukan komunikasi terapeutik dikarenakan ruangan tersebut merupakan ruangan dimana pasien baru pertama kali masuk dan perawat mengatakan komunikasi yang dilakukan adalah dalam bentuk komunikasi yang belum terlalu efektif, komunikasi terapeutik berupa strategi pelaksanaan belum bisa dilakukan karena pasien belum bisa dikendalikan hanya dengan komunikasi, pasien dikendalikan dengan obat terlebih dahulu kemudian baru bisa dilakukan komunikasi. Satu orang perawat di ruangan Epsilon mengatakan bahwa dalam melakukan komunikasi terapeutik dengan pasien tentu saja banyak hambatan yang dialami perawat, dimana hambatan terbesar banyak perawat temui pada tahap awal (pra rehabilitasi), hal itu dikarenakan, kepercayaan yang belum terbina dengan baik antara perawat dengan pasien sehingga komunikasi yang diterapkan perawat sering tidak tersampaikan dengan baik.

Satu orang perawat diruangan Pegamengatakan hambatan/kesulitan saat berinteraksi dengan pasien perilaku kekerasan ialah saat pasien berbicara pasien tidak nyambung/inkoheren dengan apa yang sedang dibicarakan, menunjukkan ekspresi tegang karena marah, masih sangat gelisah sehingga tiba-tiba memukul perawat. Kesulitan lainnya yang dialami perawat saat berinteraksi dengan 
pasien ialah pada saat pasien tidak mau berdiam diri dan terus mondarmandir membuat perawat sulit melakukan interaksi dengan pasien. Perawat tersebut mengatakan komunikasi terapeutik dilakukan tiga kali dalam sehari yaitu, pagi, siang dan malam.

Berdasarkan hasil observasi yang dilakukan peneliti terhadap perawat, peneliti melihat bahwa perawat sedikit meninggikan suaranya pada pasien yang agresif karena pasien tidak kooperatif saat diajak berkomunikasi, pasien terlihat ketakutan karena perawat berbicara dengan suara yang keras, sedangkan teknik komunikasi terapeutik pada pasien perilaku kekerasan adalah tidak membalas suara keras dari pasien. Kemudian diruangan Alfha peneliti mengobservasi terlihat seorang perawat sedang mengikat kaki dan tangan sebelah kanan dan kiri di tempat tidur pada pasien resiko perilaku kekerasan yang sedang mengamukpasien ini merupakan pasien yang baru masuk ke ruangan Alfa setelah dari ruangan Instalasi Gawat Darurat (IGD) dan belum pernah sama sekali dilakukan SP oleh perawat. Menurut hasil pengamatan di ruang Srikandi dari peneliti bahwa komunikasi yang terjalin antara pasien dan perawat hanya sekedarnya saja. Dan perawat diruang Srikandi tampak hanya melakukan komunikasi kepada pasien pada saat jam-jam tertentu seperti pada saat jam makan dan waktu minum obat. Perawat hanya memberikan obat dan pasien hanya menerima obat tersebut.

Pada saat peneliti melakukan observasi pada 8 orang pasien baru dan pasien yang sudah mendapatkan
SP oleh perawat pada pasien resiko perilaku kekerasan. Pada 3 orang pasien baru tampak sedang mengamuk, menendang tempat tidur sambil berbicara kotor. 3 orang pasien lainnya sudah mendapatkan SP namun hanya baru sekali dilakukan SP, pasien tampak memukul diri sendiri seperti merasa bahwa dirinya tidak berguna, tidak berdaya, pasien tampak mondarmandir dan tampak frustasi. 2 pasien lainnya yang sudah 2-3 kali dilakukan SP dan pasien terlihat tenang tetapi terkadang pasien masih tampak melakukan perilaku kekerasan pada saat gangguan kejiwaan nya kambuh dilihat dari tanda gejala nya seperti muka merah dan tegang, mengepalkan tangan yang terkadang diarahkan kepada temannya, dan berbicara kotor.

Berdasarkan permasalahan diatas, maka komunikasi terapeutik dapat mengajarkan cara-cara yang dapat dipakai untuk mengekspresikan kemarahan yang dapat di terima oleh semua pihak tanpa harus merusak (asertif), juga dapat membantu mengontrol perilaku kekerasan, sehingga peneliti tertarik untuk melakukan penelitian di Rumah Sakit Jiwa Daerah Jambi tentang Pengaruh Tahapan Strategi Pelaksanaan Komunikasi Terapeutik Pada Pasien Resiko Perilaku Kekerasan di Rumah Sakit Jiwa Daerah Provinsi Jambi tahun 2018.

\section{METODE PENELITIAN}

Penelitian ini merupakan penelitian kuantitatif dengan desain pre-experimental dengan one group pre-test and post test design, yang bertujuan untuk melihat 
perbandingan rata-rata sebelum dan sesudah perlakuan dengan komunikasi terapeutik. Untuk mengetahui pengaruh komunikasi terapeutik pada pasien resiko perilaku kekerasan di Ruang Rawat Inap Rumah Sakit Jiwa Daerah Provinsi Jambi tahun 2018. Populasi dalam penelitian ini adalah seluruh pasien resiko perilaku kekerasan yang ada di Ruang Rawat Inap Rumah Sakit Jiwa Daerah Provinsi Jambi tahun sebanyak 98 orang dengan jumlah sampel 20 responden. Penelitian ini dilakukan pada tanggal 12-19 Juli 2018. Pengumpulan data di lakukan dengan teknik proporsional random sampling dengan observasi langsung pada pasien resiko perilaku kekerasan. Analisa data dilakukan secara univariat dan bivariat dengan menggunakan uji $\mathrm{T}$ test dependen.

\section{HASIL DAN PEMBAHASAN}

Tabel 2. Skor Resiko Perilaku Kekerasan Sebelum Dilakukan Terapi Komunikasi Terapeutik di Ruang Rawat Inap Rumah Sakit Jiwa Daerah Provinsi Jambi Tahun 2018.

\begin{tabular}{llcccc}
\hline No. & \multicolumn{1}{c}{ Variabel } & Mean & $\begin{array}{c}\text { Max } \\
\text { Min }\end{array}$ & $\begin{array}{c}\text { Standar } \\
\text { Deviasi }\end{array}$ & N \\
\hline 1. & Resiko Perilaku & 40.50 & 48 & 3.980 & 20 \\
& Kekerasan Responden & & 35 & & \\
\hline
\end{tabular}

Berdasarkan tabel 2 diketahui rata-rata skor resiko perilaku kekerasan sebelum dilakukan komunikasi terapeutik masih termasuk dalam kategori berpesiko melakukan perilaku kekerasan dengan score mean 40,50. Pada saat observasi yang dilakukan peneliti sebagian besar responden masih berperilaku mengamuk (mata melotot), susah diajak berkomunikasi, dan menundukkan kepala, yang termasuk dalam perilaku aserteif dan amuk. Menurut Yusuf (2015), hal tersebut termasuk dalam perilaku yang maladaptif. ${ }^{6}$

Tabel 3. Rata-Rata Skor Resiko Perilaku Kekerasan Sesudah Dilakukan Terapi Komunikasi Terapeutik di Ruang Rawat Inap Rumah Sakit Jiwa Daerah Provinsi Jambi Tahun 2018.

\begin{tabular}{llcccc}
\hline No. & \multicolumn{1}{c}{ Variabel } & Mean & $\begin{array}{c}\text { Max } \\
\text { Min }\end{array}$ & $\begin{array}{c}\text { Standar } \\
\text { Deviasi }\end{array}$ & n \\
\hline 1. & Resiko Perilaku & 43.90 & 39 & 3.999 & 20 \\
& Kekerasan Responden & & 53 & & \\
\hline
\end{tabular}

Berdasarkan tabel 3 diketahui bahwa rata-rata skor resiko perilaku kekerasan sesudah deberikan terapi komunikasi terapeutik masih termasuk dalam kategori yang baik dengan score mean 43,90. Pada saat dilakukan observasi oleh peneliti sebagian besar responden sudah 
berperilaku baik, dimana pada saat observasi sebagian responden berperilaku bisa diajak berkomunikasi dan mudah diatur, hal ini termasuk kedalam perilaku adaptif.

Tabel 4 Pengaruh Strategi Pelaksanaan Komunikasi Terapeutik Resiko Perilaku Kekerasan Pada Pasien Gangguan Jiwa Di ruang rawat inap Rumah Sakit Jiwa Daerah Provinsi Jambi Tahun 2018.

\begin{tabular}{|c|c|c|c|c|c|c|}
\hline No. & Variabel & Mean & $\mathbf{n}$ & $\begin{array}{c}\text { Std. } \\
\text { Erro } \\
\mathbf{r}\end{array}$ & $\begin{array}{c}\text { Std } \\
\text { Deviasi }\end{array}$ & $p$-value \\
\hline 1. & $\begin{array}{l}\text { Sebelum dilakukan terapi } \\
\text { Komunikasi Terapeutik }\end{array}$ & 40,50 & 20 & .890 & 3,980 & \multirow{2}{*}{0.013} \\
\hline 2 & $\begin{array}{l}\text { Sesudah dilakukan terapi } \\
\text { Komunikasi Terapeutik }\end{array}$ & 43,90 & 20 & .894 & 3,999 & \\
\hline
\end{tabular}

Berdasarkan tabel 4 diketahui rata-rata mean sebelum dilakukan terapi komunikasi terapeutik adalah 40,50 dan sesudah dlakukan terapi komunikasi terapeutik rata-rata adalah 43,90.

Waktu penelitian ini hanya dilakukan selama 8 hari dari tanggal 12 Juli 2018 sampai dengan 19 Juli 2018. Beberapa responden pada saat penelitian berlangsung terkadang tidak fokus dengan terapi yang diberikan karena responden asik melihat teman nya yang sedang bermain di lingkungan sekitar nya. Sebagian responden juga acuh terhadap terapi komunikasi terapeutik yang di berikan dan bermalas-malasan mengisi ADL (Aktifity Daily Living) yang diberikan untuk dilaksanakan terapi komunikasi terapeutik tersebut secara mandiri, sehingga terapi komunikasi terapeutik tidak berpengaruh bagi responden.
Berdasarkan hasil diatas penelitian ini sejalan dengan teori menurut Afnuhazi (2015), manusia sebagai mahluk holistik dipengaruhi oleh lingkungan dalam dirinya dan lingkungan dari luar, baik keluarga, kelompok maupun komunitas.Dalam berhubungan dengan lingkungan, manusia harus mengembangkan strategi koping yang efektif agar dapat beradaptasi. Lingkungan interaksi akan mempengaruhi komunikasi yang efektif, suasana yang bising, tidak ada privasi yang tepat akan menimbulkan ketegangan dan ketidaknyamanan. ${ }^{5}$

Komunikasi terapeutik dalam penelitian ini dilakukan sebanyak 2 kali dalam satu hari selama 15 menit setiap satu kali pertemuan. Komunikasi terapeutik pada penelitian ini menggunakan tahapan strategi pelaksanaan resiko perilaku kekerasan dimana untuk 1 kali perlakuan SP dilakukan 2 kali dalam 1 hari. Tujuan dari penelitian ini 
melihat ada pengaruh tahapan strategi pelaksanaan komunikasi terapeutik pada pasien resiko perilaku kekerasan.

Menurut penelitian Asrin dkk (2008), mengemukakan bahwa komunikasi terapeutik yang diberikan kepada pasien dapat dijalankan dalam waktu satu shift tugas (shift pagi, siang, dan malam). Hasil penelitian ini menunjukkan adanya hasil yang signifikan dengan hasil 93,3\% responden mengatakan puas dan sangat puas terhadap teknik komunikasi terapeutik yang dilakukan oleh perawat. ${ }^{7}$

Menurut Yusuf (2015), tanda gejala yang sering muncul pada pasien dengan resiko perilaku kekerasan seperti emosi (tidak adekuat, tidak mana, rasa terganggu, marah/dendam, jengkel), intelektual (mendominasi, bawel, berdebat, meremehkan), fisik ( muka merah, pandangan tajam, tangan mengepal, napas pendek, keringat, sakit fisik, penyalahgunaan zat, TD meningkat), spiritual (kemahakuasaan, kenijakan/kebenaran diri, keraguan, tidak bermoral, kebejatan), sosial (menarik diri, pengasingan, penolakan, kekerasan, ejekan, humor). ${ }^{6}$

Menurut Yosep (2016), salah satu penatalaksanaan dari resiko perilaku kekerasan adalah komunikasi. Untuk berkomunikasi dengan klien perilaku kekerasan sebaiknya bersikap tenang, bicara lembut, bicara tidak dengan cara menghakimi, bicara netral dan dengan cara konkrit, tunjukkan rasa hormat, hindari intensitas kontak mata langsung, demonstrasikan cara mengontrol situasi, fasilitasi pembicaraan klien dan dengarkan klien, jangan terburu-buru menginterpretasikan dan jangan buat janji yang tidak bisa ditepati.

Stuart dan Sundden (1998) dalam Pieter (2017), menyatakan bahwa komunikasi terpeutik merupakan hubungan interpersonal antara perawat dengan pasien, dalam hubungan ini perawat dan klien memperoleh pengalaman belajar bersama dalam rangka memperbaiki pengalaman emosional pasien (klien). Dengan demikian hubungan terpeutik merupakan suatu hubungan yang bersifat kerja sama yang bersifat terpeutik yang ditandai adanya pertukaran perilaku, perasaan, pikiran dan pengalaman dalam membina hubungan intim yang terapeutik. Jadi dapat disimpulkan bahwa komunikasi terapeutik dapat meningkatkan hubungan perawat dengan klien dan bisa membantu pasien untuk mengontrol emosi sehingga dapat menurunkan resiko perilaku kekerasan. $^{8}$

Berdasarkan uraian diatas dapat disimpulkan bahwa pengaruh tahapan strategi pelaksanaan komunikasi terapeutik pada pasien resiko perilaku kekerasan hal ini dikarenakan komunikasi terapeutik dapat meningkatkan interaksi antara perawat dengan pasien. Dimana perawat bisa menjadi teman pasien untuk berbagai cerita tentang permasalahan yang dihadapi pasien sehingga secara tidak langsung pasien memiliki ikatan emosional dengan perawat.

Hal ini bisa menjadi salah satu cara untuk mengendalikan emosi sehingga dapat menurunkan resiko perilaku kekerasan.Dan diharapkan perawat untuk dapat lebih 
meningkatkan komunikasi terapeutik dan agar dapat dilaksanakan secara terus menerus supaya pasien dengan resiko perilaku kekerasan mengalami perubahan perilaku maupun sikap yang lebih baik (adaptif).

\section{SIMPULAN}

Berdasarkan hasil penelitian dan pembahasan yang diperoleh maka dapat ditarik kesimpulan sebagai berikut :

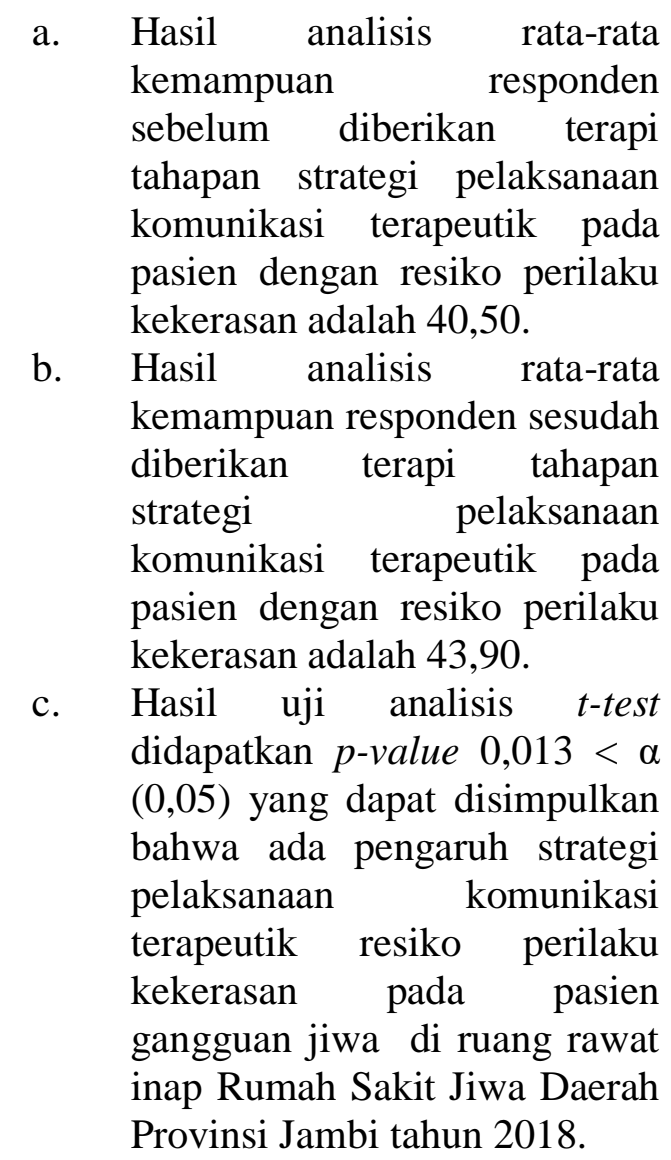

\section{SARAN}

a. Bagi Rumah Sakit Jiwa Daerah Provinsi Jambi
Informasi yang didapatkan dari hasil penelitian ini dapat menjadi tambahan informasi bagi perawat untuk lebih meningkatkan komunikasi terapeutik dimana komunikasi antar perawat dengan pasien dengan cara berinteraksi sesuai Strategi Pelaksanaan sesuai tahapannya. Perawat diharapkan melakukan komunikasi terapeutik dengan pasien sebanyak 3 kali atau lebih dalam sehari supaya terjalinnya hubungan interpersonal antara perawat dan pasien dan mempercepat proses penyembuhan pasien.

b. Bagi Institusi Pendidikan

Diharapkan dapat menjadi tambahan bahan masukan untuk menambah wawasan bagi institusi pendidikan kesehatan sehingga dapat meningkatkan pengetahuan tentang pengaruh komunikasi terapeutik dengan menggunakan strategi pelaksanaan pada pasien jiwa khususnya pasien dengan resiko perilaku kekerasan.

c. Bagi Peneliti Selanjutnya

Untuk peneliti selanjutnya diharapkan kepada peneliti selanjutnya jika ingin melaksanakan penelitian dengan variabel yang sama agar memberikan strategi pelaksanaan komunikasi terapeutik pada pasien resiko perilaku kekerasan 3 kali melakukan komunikasi dalam sehari agar didapatkan hasil lebih baik dari penelitian sebelumnya. 


\section{DAFTAR PUSTAKA}

1. Yosep Iyus. (2016). Buku Ajar Keperawatan Jiwa.Yogyakarta : Refika Aditama

2. Riset Kesehatan Dasar. (2013). Kesehatan Jiwa.www.depkes.go.id.

Diakses tanggal 09 April 2018 pukul 10.55 WIB.

3. Ikatan

Dokter

Indonesia.(2016). Hari

Kesehatan Jiwa Sedunia :

Penyebab Munculnya

Gangguan Kesehatan

Jiwa.http://www.idionline.or

g/berita/hari-kesehatan-jiwasedunia-penyebab-

munculnya-gangguan-

kesehatan-jiwa/. Diakses

tanggal 15 April 2018 pukul 14.55 WIB.

4. Damaiyanti

M.

(2008).Komunikasi

Terapeutik dalam Praktik Keperawatan.Bandung : Refika Aditama.

5. Afnuhazi Ridhyalla. (2015). Komunikasi Terapeutik
Dalam Keperawatan

Jiwa.Yogyakarta: Gosyen Publishing

6. Yusuf dkk.(2015). Buku Ajar Keperawatan Kesehatan Jiwa. Jakarta: Salemba Medika.

7. Asrin, dkk. (2008). Gambaran Praktik

Komunikasi Terapeutik Dan Komunikasi Isosial Perawat Dalam Pemberian Pelayanan Keperawatan. Diakses tanggal 10 Agustus 2018 pukul 17.30 WIB.

8. Pieter Herri Zan. (2017).

Dasar-dasar Komunikasi Bagi Perawat. Jakarta, PT. Kharisma Putra Utama

9. Witojo Djoko \&Widodo Arif.(2008). Pengaruh Komunikasi Terapeutik Terhadap Penurunan Tingkat Perilaku Kekerasan Pada Pasien Skizofrenia.Surakarta : Perawat RSJD. Surakarta \& Dosen Keperawatan FIK UMS. 